\title{
LA ESCULTURA ROMÁNICA Y SUS PROBLEMAS DE INTERPRETACIÓN: EL LLAMADO SEPULCRO «DE MUDARRA» PROCEDENTE DEL MONASTERIO DE SAN PEDRO DE ARLANZA *
}

\author{
POR \\ JOSÉ L. SENRA GABRIEL Y GALÁN \\ Universidad de Santiago de Compostela
}

\begin{abstract}
The legendary traditions created in monasteries during the Middle Ages and revitalized in modern times have often led to mistaken interpretations of their oldest remains, both architectural and in the minor arts. One of these remains is the mural monument today in the cloister of the Cathedral of Burgos and originally from the Monastery of San Pedro de Arlanza. Known as the «Tomb of Mudarra» (hero of the County of Castilla), in the traditional historiography it came to be considered a work of the early Romanesque or even a falsification from the seventeenth century. This article attempts to delve into the process by which the mural monument aquired its mythic meaning. A stylistic analysis will resituate the mural monument in the historical context of the late Romanesque in which it was created.
\end{abstract}

Una de las constantes con las que hemos de enfrentarnos a la hora de estudiar un edificio medieval —como ente histórico- es su frecuente apropiación por parte de la leyenda. En ocasiones se trata de una auténtica maraña de datos enriquecidos progresivamente con idéntica dinámica a la de un poema épico, que ha dificultado, en ocasiones enormemente, una interpretación objetiva y verídica de su realidad. El caso de los monasterios benedictinos castellano-leoneses no es una excepción; a lo largo de su intensa historia un cortinaje mítico - promovido por los propios monjes - ha encubierto una realidad, a veces más sugestiva, incluso, que la propia leyenda. Antigüedad y gloria se traducían en prebendas y favores concedidos por una nobleza ávida de ser enterrada en estos recintos de oración y santidad cada vez más desplazados por nuevas órdenes religiosas. Es así como el claustro del monasterio de Silos se atribuía al propio Santo Domingo (+1076), el resto que aún se mantiene en San Pedro de Cardeña a la época de la matanza de los monjes a manos de los musulmanes en el siglo IX, o la primera iglesia monástica de San Facundo y San Primitivo de Sahagún al mismo Carlomagno. Hoy sabemos que las dos primeras fueron realizadas en el curso de la pri-

\footnotetext{
* Agradezco al Cabildo de la catedral de Burgos, y especialmente al P. Matías Vicario Santamaría las facilidades prestadas para la toma de datos del sepulcro llamado de Mudarra. Este artículo fue presentado como comunicación no publicada en la 2. ${ }^{\underline{a}}$ Semana de arte y cultura en los monasterios del Ripollés: trabajo y creación en la escultura románica (Ripoll-Sant Joan de les Abadesses-Camprodon, 13-15 de julio de 1994).
} 
mera mitad del siglo XII y sobran comentarios sobre la posibilidad de una iglesia carolingia en una población, Sahagún, que ni tan siquiera existía en el siglo IX. En esta dinámica, el monasterio de San Pedro de Arlanza, siempre a remolque de un vecino tan incómodo como Silos, además de pretender responsabilizar de su fundación a un monarca visigodo - Wamba (672-680)—, al igual que Cardeña con el Cid, cultivó activamente la fama del más insigne de sus difuntos, el conde Fernán González. Entre 1250-52 un monje del monasterio codificó la tradición legendaria del conde en el Poema de Fernán González. Varios siglos después el abad Gonzalo de Arredondo (1512-1521), que concluyó la reforma tardogótica del templo, llevó a cabo otra conocida compilación apologética. La fascinación por este personaje a lo largo de toda la Edad Media llegó al punto de que su sepultura fuera abierta en varias ocasiones para obtener alguno de sus despojos a modo de reliquia, como parece que ocurrió con Fernando III antes de partir a conquistar Sevilla en $1246^{1}$, o con el simple objeto de contemplarlos, caso de Enrique IV a mediados del siglo XV (1458) ${ }^{2}$. En tal clima de fervor la leyenda quería que en el curso de las grandes batallas sus huesos se agitaran dentro del sepulcro produciendo golpeteos ${ }^{3}$. Sabemos que sus restos fueron trasladados a fines del siglo XI desde la antigua iglesia de San Pedro el Viejo, en donde debieron reposar desde su fallecimiento, al pórtico de la iglesia románica, lugar en el que estuvieron situados hasta el siglo XIII. En 1274, y al igual que hicieron algunos años más tarde otros centros monásticos con sus difuntos más insignes, fueron introducidos, junto a los de su esposa, en el interior del templo ${ }^{4}$. Quizá a este momento responda el sobrio sepulcro del conde, en claro contraste con el hispanorromano de su esposa ${ }^{5}$. En 1369 ambos se colocaron en el tramo del presbiterio en donde fueron objeto de constante veneración ${ }^{6}$. Al igual que ocurrió con muchos otros personajes mitificados se llegó a identifi-

1 Prudencio de Sandoval: Historias de Idacio, obispo, que escrivió poco antes que España se perdiese; de Isidoro obispo de Badajoz; de Sebastiano, obispo de Salamanca; de Sampiro, obispo de Astorga; de Pelagio, obispo de Oviedo, nunca hasta ahora impresas, con otras notas tocantes a estas historias y reyes dellas. Pamplona 1615 , p. 334. En adelante Cinco obispos.

2 «Y de ally fué al monasterio de Arlanca, donde está enterrado el conde Fernán Gonçales, al qual su alteza mandó descobrir en la sepultura donde estaua, y lo vido, y el señor Condestable con él» (Hechos del Condestable Don Miguel Lucas de Iranzo (J. de Mata Carriazo, ed.). Madrid 1940, pp. 22-23.

3 «El dia que se entraron, y ganaron Seuilla, y Granada se oyeron grandes golpes dentro de su sepultura» (Sandoval: Cinco Obispos, 334). Sobre esto ver: Ramón Menéndez Pidal: La epopeya castellana a través de la literatura española. Buenos Aires 1945, p. 46.

${ }^{4}$ A fines de ese mismo siglo se introdujeron las sepulturas del panteón regio de San Benito de Sahagún, y en San Salvador de Oña fue construida una capilla funeraria. Ambas fueron iniciativas de Sancho IV. Sobre esta cuestión: José Luis Senra: «El monasterio de Oña como panteón regio». Comunicación presentada al II Curso de Cultura Medieval (en prensa); Fernando Gutiérrez Baños: Las empresas artísticas de Sancho IV el Bravo. Burgos 1997, pp. 152-163.

Fray Justo Pérez de Urbel: Fernán González el héroe que hizo a Castilla. Buenos Aires 1952, p. 184. En el sepulcro se colocó la palabra OBIIT así como «sus ynsignias y pendón y sus armas conjunto con la sepultura adonde oy día están» (Gonzalo de Arredondo: Chronica del Bienaventurado Catholico Caballero el Conde Fernan Gonçalez. 1622 (h.1513-14), Ms de la Biblioteca Nacional, fol. 264). Sobre esto también, Sandoval: Cinco obispos, 333; Rodrigo Amador de los Ríos: Las ruinas del monasterio de San Pedro de Arlanza. Estudio histórico-arqueológico. Madrid 1896, p. 4). Sobre el sepulcro romano llamado de «Doña Sancha» en su contexto medieval: Serafín Moralejo: «La reutilización e influencia de los sarcófagos antiguos en la España medieval». En: Colloquio sul reimpiego dei sarcofagi romani nel medioevo (Pisa, 5-12 september 1982). Marburg 1984, pp. 189-191, fig. 3 .

Luciano Huidobro Serna: «El monasterio de S. Pedro de Arlanza y su primer compendio historial inédito». Boletín de la Sociedad Espanola de Excursiones, 7 (1924), p. 203; id., 20 (1927), pp. 212-213. Hasta el testimonio de fr. Juan de Pereda (1563), dado a conocer por Huidobro, se desconocía la fecha del traslado. Amador de los Ríos había señalado que respondería a la primera mitad del siglo XIII (Ríos: Las ruinas, p. 7, n. 2) basándose en que el Poema de Fernán González (c. 1250), al referirse a la nueva iglesia que construyera el conde 
car como suyos ciertos objetos del tesoro monástico como fue el caso de dos cruces desaparecidas de más que probable cronología posterior ${ }^{7} \mathrm{o}$ el de la recientemente rescatada «Virgen de las Batallas», obra de pleno siglo XIII ${ }^{8}$.

Pero la búsqueda de prestigio fue más allá y ya en época moderna se buscaron nuevos recursos para potenciar la atracción de las élites nobiliarias.

\section{La historiografía moderna y el sepulcro «de Mudarra».}

A instancias de la Comisión de Monumentos de Burgos y por cesión de su antiguo propietario, el 19 de abril de 1896 se trasladó el sepulcro desde el claustro de Arlanza al superior de la catedral burgalesa ${ }^{9}$ en cuyo ángulo fue montado por el entonces arquitecto restaurador de la fábrica, Vicente Lampérez y Romea (fig. 1) ${ }^{10}$.

La mítica figura de Mudarra González forma parte fundamental en el desenlace de la Leyenda de los infantes de Lara o de Salas ${ }^{11}$. Hijo bastardo de Gonzalo Gustioz — padre de los

le hace decir que «fare dentrro en ella el mi soterramiento» (Poema de Fernán González (ed A. Zamora Vicente). Madrid 1978 (1946), p. 74). En 1841 ambas sepulturas fueron llevadas a la colegiata de Covarrubias en cuyo presbiterio hoy se contemplan (Rodrigo Amador de los Ríos: España, sus monumentos y artes, su naturaleza e historia. Burgos. Barcelona 1888, p. 880).

7 «Es cosa sin duda, que vna gran Cruz de plata, que esta en la Sacristía, es la que el Conde llebaua por estandarte en su campo, en la hechura figuras, parece mucho a la de nuestra señora de Covadonga, tiene a Christo clauado cada pie por si, y encima de la cabeça con letras Goticas de plata, I.N.R.I. Debaxo de los pies de Christo esta Adan, como que se lebanta de la sepultura,...» (Sandoval: Cinco Obispos (1615), p. 334). También en: Fray Juan de Arévalo: Coronica de los antiguos condes y primeros reyes y señores de Castilla, la mas cumplida, o por mejor decir la primera, que en quanto a los condes hasta aora ha salido. Trata tambien de los Reyes de Leon, Nauarra, v Aragon, que ha hauido desde la perdida de España hasta la muerte del Rey Don Alonso el Sesto. Tambien se pone la historia del Çid Ruy Diaz muy aueriguada v cierta (h.1621). Ms. de la Biblioteca de la Real Academia de la Historia, fol. 115-115v. Junto a esta cruz se conservaba otra de tipo «patriarcal» que se suponía llevaba el conde en las batallas (Sandoval: Cinco Obispos, p. 352; Vicente de la Fuente: «La cruz patriarcal, ó de doble traversa, y su antigüedad y uso en España; a propósito de la cruz de Caravaca». Boletín de la Real Academia de la Historia, IX (1886), p. 184; Eloy García de Quevedo: «San Pedro de Arlanza: monasterio de la provincia de Burgos». Boletín de la Sociedad Española de Excursiones, 13 (1894), pp. 56-58; «Un 'lignum crucis' famoso». Boletín de la Comisión Provincial de Monumentos Históricos y Artísticos de Burgos, 84-85 (1943), pp. 278-281.

8 «Persevera una imagen de Nuestra Señora que el Conde llevaba también a las campañas y la llaman de las batallas» (Enrique Flórez: España Sagrada. Madrid 1772, tomo XXVII, col. 151-152).

9 Ríos: Las ruinas, pp. 24-25, n. 3; Eloy García de Quevedo y Concellón: «Excursiones por la provincia de Burgos». Boletín de la Sociedad Española de Excursiones, VII (1899), p. 203; Luciano Huidobro: «El monasterio de S. Pedro de Arlanza y su primer compendio historial inédito» (1924), pp. 204-207.

10 Manuel Ayala López: La catedral de Burgos. Antecedentes históricos: descripción de su traza, nave, coro, capillas, claustros y cuantas preciosidades artísticas contiene. Burgos 1950, p. 94.

${ }_{11}$ Sobre esta leyenda, cuyos hechos responderían a una realidad histórica situada en el último cuarto del siglo X: Ramón Menéndez Pidal: La leyenda de los infantes de Lara. Madrid 1934 (1896); Fr. Justo Pérez de Urbel: Historia del Condado de Castilla. Madrid 1945, tomo II, pp. 735-754 y, más recientemente: Antonio Garrosa Resina: «La Leyenda de los siete Infantes de Salas: contribución literaria al conocimiento de la vida en el antiguo Condado de Castilla». Castilla (Boletín del Departamento de Literatura Española. Universidad de Valladolid), n. $.2-3$ (1981), pp. 77-120. J.M. Ruiz Asencio ha ratificado las sospechas de Pérez de Urbel de que los acontecimientos históricos narrados por la leyenda pudieron desarrollarse hacia 990 («La rebelión de Sancho García, heredero del condado de Castilla». Hispania Sacra, XXII (1969), pp. 23 y ss.). Sobre las diversas versiones textuales, ver más recientemente: Alan Deyermond: La literatura perdida de la Edad Media castellana. Catálogo y estudio. I-Épica y romances. Salamanca 1995, pp. 55-72. En cuanto al topónimo Lara, seguramente no anterior al siglo XIII (Paloma Díaz Mas (ed.): Romancero. Madrid 1994, p. 57, n.. 17), fue reconsiderado en posteriores trabajos por Menéndez Pidal a partir de que el nacimiento de los infantes debió producirse en la villa de Salas, hoy Salas de los Infantes (Burgos). 
infantes - y una hermana del mismo Almanzor, el llamado «hijo de la renegada» recibió su educación del propio caudillo musulmán, vengando la muerte de sus hermanastros ${ }^{12}$. Al menos desde el siglo XVI los monasterios de San Millán de la Cogolla y San Pedro de Arlanza pujaron por la pretensión de conservar la sepultura de los siete jóvenes asesinados ${ }^{13}$. El apasionamiento llevó a que en 1600 el abad del monasterio riojano, fray Plácido de Alegría, procediera a la apertura notarial de los siete sarcófagos ubicados en el pórtico del primitivo asentamiento en Suso, a fin de certificar su autenticidad. La aparición de los cadáveres descabezados fue prueba que, poco tiempo después convenció tanto a Sandoval como a Yepes para sellar la contienda a favor de la Cogolla ${ }^{14}$. Años antes, en diciembre de 1569 , se habían encontrado en la iglesia parroquial de la villa de Salas «las cabeças de los siete Infantes dentro de vn arca de madera, cubiertas con vn lienço» ${ }^{15}$.

12 «Et este fue el que uengo a su padre et a sus hermanos los VII infantes por la traycion que les boluiera Roy Blasquez,...» (Primera Crónica General (ed. R. Menéndez Pidal). Madrid 1977 (1955), tomo II, pp. 435-436. Ver también: Crónica Geral de Espanha de 1344 (L.F. Lindley Cintra, ed.). Lisboa 1961, tomo III, pp. 138-172; Romancero (ed. P. Díaz-Mas). Madrid 1994, pp. 55-72.

13 Ambrosio de Morales apostaba por la veracidad de la reivindicación de Suso: «Los cuerpos de los Infantes, recogidos por algunos leales caballeros, fueron llevados á Castilla, y enterrados en el Monesterio de San Pedro de Arlanza, donde los Monges muestran sus sepulturas, y lo mismo hacen los de San Millán de la Cogolla, donde parece mas verosimil fuesen llevados, por ser harto léjos de donde Ruy Velazquez, que tan fieramente los trató en vida les pudiese intentar alguna injuria en la sepultura» (Ambrosio de Morales: Crónica General de Espana. Madrid 1791, tomo VIII, p. 313). En 1571 Esteban de Garibay señalaba que «los cuerpos d'estos siete infantes cobrados de poder de los Moros, refiere se, que fueron sepultados en el monesterio de Sant Pedro de Arlança, donde los monjes de aquella casa muestran su sepultura, pero los religiosos d'el monesterio de Sant Millian de la Cogolla tienen vnas antiguissimas sepulturas de piedra, en numero de nueue, cuyo assiento es en la claostra a la entrada de la yglesia, en la puerta que llaman de los condes, que es en el antiguo monesterio, donde affirman estar sepultados los siete infantes y su padre, Gonçalo Gustios, y su ayo Nuño Sallido. Cierto que estas nueue sepulturas denotan grande antiguedad, pero no me determinaria a dezir, si estan aqui, o en Arlança. Ay en estas cosas tanta confusion, que como adelante lo apuntaremos, muestran en Sant Pedro de Arlança la sepultura de Don Gonçalo Gustios, y de su muger Doña Sancha nasciendo, y estos negocios de querer los religiosos atribuyr a sus casas auctoridad y antiguedad con las sepulturas de semejantes caualleros, que eran de la mayor estima y valor, que auia en Castilla» (Esteban de Garibay: Los XL libros del compendio historial de la chronicas y universal historia de todos los reynos de España. Amberes 1571, tomo I, p. 540). Por su parte, Juan de Mariana se hacía eco de la polémica: «Sobre el lugar en que los siete hermanos fueron sepultados, hay contienda entre los monges de aquel monasterio y de San Millán de la Cogulla ¿que juez los podrá poner en paz?» (Juan de Mariana: Historia General de España (E. Chao, ed). Madrid 1849 (1601), tomo I, pp. 397-398).

${ }_{14}$ «Y assi a tres dias del mes de Diziembre del año 1600 ante el Alcalde del Valle, llamado Felices de Vreta, y escriuano Diego de Miranda, y muchos testigos, el padre fray Placido de Alegría, Abad de san Millan, mandò abrir las dichas sepulturas, quitando de encima dellas las grandes piedras que las cubrían: no se hallo mas de vna sola cabeça con su cuerpo en vna sepultura, y las demás sin cabeças: por donde queda llano y sin duda ser los siete Infantes, conforme a la tradicion» (Prudencio de Sandoval: Primera parte de las fundaciones de los monasterios del glorioso Padre San Benito. que los reyes de España fundaron y dotaron, desde los tiempos del santo, hasta que los Moros entraron y destruyeron la tierra y de los santos y claros varones desta sagrada Religión que desde el año DXL que San Benito embio sus Monges, hasta el año DCCXIIII que fue la entrada de los Moros Africanos, han florecido en estos Monasterios. Madrid 1601, fol. 89. En adelante Fundaciones); Antonio de Yepes: Crónica General de la Orden de San Benito (ed. Fr. J. Pérez de Urbel). Madrid 1959 (1615), tomo I, pp. 81-82. A fines del XVIII Jovellanos veía a la entrada de la iglesia los sepulcros encalados «en forma de ocho grandes baules» refiriendo: «veré si existe en el archivo algún apoyo de la tradición de ser ciertos» (Gaspar Melchor de Jovellanos: Obras (ed. M. Artola). Madrid 1956, tomo III, p. 278). En la actualidad se contemplan en el mismo lugar.

${ }_{15}$ Sandoval: Cinco Obispos, p. 354. Añadía que la propia madre de los infantes reposaba en el monasterio de Arlanza, omitiendo cualquier alusión a Mudarra (id., p. 364). Sobre Salas ver también, Sandoval: Fundaciones (1601), fol. 89, y Yepes: Crónica general de la orden de San Benito, I, p. 82. Este último señala 1597 como fecha de la inspección que dio como resultado el hallazgo. Todavía hoy se conserva en su iglesia de Santa María la arqueta en la que fueron depositadas una vez descubiertas. 
La reacción de la comunidad de Arlanza no tardó en llegar, ya que, por lo que sabemos, la primera identificación documentada de la sepultura del héroe castellano arranca de la segunda mitad del siglo XVI ${ }^{16}$. En 1563 el monje del monasterio fr. Juan de Pereda nada decía de ella ${ }^{17}$. Unos años después, en 1571, Esteban de Garibay y Zamalloa, que pudo ver el arcosolio en su contexto románico presumiblemente original, señalaba que los monjes de Arlanza mostraban en el claustro la sepultura de este personaje «en vna losa grande, sin señalar el tiempo de su muerte, ny otra cosa», junto a la que estaba su esposa ${ }^{18}$, noticia que repetirían sucesivamente Ambrosio de Morales, en $15866^{19}$, y Juan de Mariana, en $1601{ }^{20}$. Paradójicamente, en 1615, Yepes y Sandoval omiten dato alguno sobre el asunto. Llegados a este punto resulta obligado preguntarse si harían alusión aquéllos al arcosolio que nos ocupa.

La sustitución del primitivo claustro por el actual, justamente en los años previos a 1617, fue ocasión para subrayar la tradición mítico-legendaria del monasterio. De este modo, en el centro de la panda occidental e inserta en el muro, fue ubicada una caja sepulcral con caracteres coetáneos no disimulados, en los que todavía se leě que ahí reposaba Belasco, uno de los lugartenientes del conde castellano según el Poema (Cap. XVIII, 460). Esta reforma del claustro debió preservar el arcosolio en su antigua ubicación. Hasta mediados del XIX —abandonado el monasterio por los monjes tras la Desamortización — no encontramos ninguna referencia directa sobre ella. Fue entonces cuando las ruinas atrajeron la curiosidad de diversos estudiosos, fruto de lo cual aparecieron una serie de artículos de carácter científico que trataron de definirlas. Por vez primera se nos indica su exacta localización, en el ángulo noroeste de la panda occidental del propio claustro, junto a la puerta barroca de entrada a la iglesia ${ }^{21}$. En 1847 Rafael Monje abría un desmitificador artículo sobre el monasterio señalando que «la historia general amalgama las pocas verdades que cuenta con anécdotas maravillosas e increíbles». Consideraba el edículo sepulcral como «copia bien entendida», realizada durante la sustitución del claustro románico a comienzos del siglo XVII ${ }^{22}$. Señalaba, además, por primera vez, la falsedad de una tradicional identificación con la figura del héroe castellano Mudarra ${ }^{23}$. Años más tarde Ro-

${ }^{16}$ Gonzalo de Arredondo nada señala a propósito de su sepultura (Arredondo: Chronica del Bienaventurado Catholico Caballero el Conde Fernan Gonçalez, fols. 280v y ss.).

17 Este monje de Arlanza es autor de una historia manuscrita del monasterio (Compendio historial del Real Convento de San Pedro de Arlanza), hoy lamentablemente perdida, que conocemos indirectamente a través de dos breves artículos de Luciano Huidobro que pudo consultarla, aunque no dejó escrito dónde (ver nota 8).

${ }_{18}$ «Muestrase la sepultura de Mudarra Gonçalez, en la claostra d'el monasterio de Sanct Pedro de Arlança, en vna losa grande, sin señalar el tiempo de su muerte, ny otra cosa» (Garibay: Los XL libros (1571), I, p. 543).

${ }_{19}$ Morales añadía que allí enseñaban también la sepultura de su padre y, al igual que la anterior, con sus epitafios. Asimismo hacía arrancar de este personaje a la familia de los Manriques (Morales: Crónica (1586) VIII, p. 401).

${ }_{20}$ Mariana: Historia General de España 1849 (1601) I, p. 397. En estos mismos años se dramatizaron algunos romances legendarios, entre los que no podía faltar el de los Infantes. En 1579 Juan de la Cueva escribía la tragedia Los siete infantes de Lara y en 1612 Lope de Vega El bastardo Mudarra.

${ }^{21}$ Ríos: Burgos (1888), pp. 892-893. Asimismo apuntaba su reconstrucción en ese lugar tras la sustitución del claustro (Las ruinas (1896), p. 16).

${ }^{22}$ El sepulcro «ha sido objeto de los mayores elogios, como ejemplar auténtico de un estilo, proscrito hace siete siglos en España». Para él «las imitaciones en tiempos lejanos pudieron muy bien hacerse como en nuestros días por varias causas» una de las cuales sería el «sostener entre los pueblos el concepto de esa ancianidad venerable, que las tradiciones históricas velan con la nube del misterio, para confundir sus extremos y extraviar en el camino que á ellos guía á la incrédula rivalidad, hija del fanatismo y las pasiones» (Rafael Monje: «El monasterio de San Pedro de Arlanza». Semanario Pintoresco Español, 25 de julio de 1847, pp. 234-235).

23 El diccionario de Madoz seguía la tradición, señalando entonces sobre Arlanza que «también se colocó en sus claustros el sepulcro de Mudarra» (Pascual Madoz: Diccionario geográfico-estadístico histórico de España y sus posesiones de Ultramar. Madrid 1849, tomo II, p. 567). 
drigo Amador de los Ríos, si bien coincidía con este último aserto, reaccionaba contra la contundente propuesta de falsedad que juzgaba peregrina ${ }^{24}$. Abogando por la autenticidad, alegaba para ello diversos detalles que acreditaban «el despiece primero, y la reconstrucción después, en el siglo XVII» ${ }^{25}$.

\section{Una accidentada cronología: el problema de la lauda de Godo.}

Junto a la caja sepulcral todavía puede verse una lauda con forma trapezoidal achatada y dos aguas separadas por un friso plano que contiene una inscripción, de la que se han realizado diferentes y encontradas transcripciones y a partir de la cual se ha datado ${ }^{26}$. El principal problema que ha planteado el edículo funerario radica, precisamente, en la inseguridad de que esta lauda perteneciera al arcosolio desde su origen o fuera resultado de un añadido posterior. Como consecuencia de una errónea lectura de la inscripción Garibay identificó la lauda con una hipotética mujer del héroe, situando su fallecimiento en 1025 (ERA MLXIII) ${ }^{27}$. Afortunadamente, a través de una obra de Ambrosio de Morales, hoy perdida, que precisaba el, por otro lado, ambiguo testimonio de su contemporáeo Garibay, sabemos que la lauda se encontraba en una «capillita en la pared» de la sala capitular, en donde había «dos sepulturas, una sobre otra: la de arriba dicen ser de un Rey Godo». Es decir, la referencia dada a conocer por el historiador guipuzcoano sobre la sepultura de Mudarra haría alusión a uno de los nichos del capítulo. Por otra parte, Morales procedía a una transcripción del epígrafe malinterpretando la cifra centesimal (ERA MEXIII); según señalaba, sería el año $975^{28}$. De esta manera, no ha de extrañar que en 1847 Rafael Monje describiera el sepulcro acompañado de

24 «Dejando, pues, á un lado empeño semejante, estéril de por sí y ocasionado por el humorismo del escritor burgalés á quien hacemos referencia, puédese desde luego y sin vacilación alguna afirmar que la tumba del claustro procesional de este Monasterio de Arlanza es documento de verdadero interés, no por lo que la tradición y la conseja respecto de él afirman, suponiendo gratuitamente que fué labrado para contener las cenizas del famoso Mudarra, sobrino de Al-Manzor, según quiere la leyenda sino por su carácter artístico y su valor arqueológico, según lo han confesado escritores posteriores, concediéndole, ó por mejor decir, reconociéndole como una de las preseas más dignas de estima en aquella santa casa» (Ríos: Burgos (1888), pp. 901-902).

25 «No hubiera éste, sin embargo, llegado al punto que expresan sus palabras, si con la detención debida hubiera reparado en multitud de detalles, tales como el ensamblaje y juntura de los sillares, la construcción, por ejemplo, de las enjutas del grande arco exterior, donde con entera claridad se proclama y patentiza cuanto dejamos consignado, y muy principalmente con los soportes interiores, acanalados cual los exteriores, imnediatos á las columnas, la forma en que se ofrece la imposta de la derecha del espectador, la cual no descansa directamente sobre el cimáceo del capitel de ese lado, como en el contrario ocurre, sino que ha sido recalzada visiblemente, acreditando así el despiece primero y la reconstrucción después en el siglo XVII del monumento á que aludimos» (Ríos: Burgos (1888), p. 902).

${ }_{26}$ Esta morfología, tal y como ha señalado Serafín Moralejo para la lauda de Alfonso Ansúrez, aparece ya en la del sepulcro de Itacio de Oviedo (siglo VI) («The Tomb of Alfonso Ansúrez $(+1093)$ : Its Place and the Role of Sahagún in the Beginnings of Spanish Romanesque Sculpture». En: Bernard F. Reilly (ed.): Santiago Saint-Denis and Saint-Peter: The Reception of the Roman Liturgy in Leon-Castille in 1080. New York 1985, p. 65, nota 15).

27 «A su lado, está otra sepultura de piedra, de su muger, donde puesto caso, que no se manifiesta su nombre, nota se auer falecido en la Era de mil y sesenta y tres, que es ano d'el nascimiento de mil y veynte y cinco» (Garibay: Los XL libros (1571), p. 543). Como ya señaló Menéndez Pidal, el historiador guipuzcoano entendió la cifra centesimal por una L; es decir, MLXIII, en vez de MCXIII (Menéndez Pidal: La leyenda de los infantes de Lara 1934 (1896), p. 181. n. ${ }^{\circ}$ 2).

28 «El Capitulo se hace en una Capilla muy antigua y galana en la claustra, en la qual estan sepultados muchos Prelados y caballeros y en una Capillita en la pared hay dos sepulturas una sobre otra: la de arriba dicen ser de un Rey Godo y tiene este letrero como aqui ba: HOC: IH LOCO: REQESCIT / FATA: DEI: GODO: II: HNS / FBRI: IN: ERA: M: E: XIII» (José Cornide: Inscripciones sacadas de un manuscrito existente en la Biblioteca de los Estudios de San Ysidro de Madrid el qual tiene por titulo «Memorial de las cosas antiguas de 
un dibujo en el que no aparecía la lápida — de la que no hacía siquiera referencia—y sí una hilera de ladrillos (fig. 2) ${ }^{29}$. Rodrigo Amador de los Ríos fue quien en 1889, por primera vez, mostró dudas sobre la repentinamente nueva ubicación de la lauda en el arcosolio ${ }^{30}$, opinión a la que se sumaron más tarde García de Quevedo ${ }^{31}$ y Pérez Carmona ${ }^{32}$. Independientemente, un análisis detallado, tanto del tipo de piedra de la lauda como de su propia morfología, apuntan hacia su indiscutible añadido en fecha indeterminada de mediados del siglo XIX ${ }^{33}$.

Así pues, y a modo de primera conclusión, todo hace suponer que la lauda fue trasladada desde otra ubicación, probablemente desde la sala capitular, en uno de cuyos nichos fue vista a fines del siglo XVI, junto a otra carente de inscripción, por Garibay y Morales que aportaron sendas lecturas del epígrafe. El primero recogió la tradición que identificaba el propio arcosolio con la sepultura de Mudarra, en el que se encontraba también el sepulcro de su esposa - para él la lauda con inscripción—; el segundo, haciéndose eco por vez primera de la noticia, ignoraba posteriormente la vinculación con el héroe y aportaba una nueva tradición, derivada de una errónea lectura, según la cual la lápida situada en la parte superior pertenecería, según su epígrafe, a un «rey Godo». Mediado el pasado siglo y con el monasterio sumido en una degradación que aún no se ha detenido, seguramente se procedió a colocarla sobre la base del arcosolio tardorrománico del claustro, dándole un contenido mítico del que sin duda carecía. Consecuentemente se enmascaraba su realidad histórica, condicionando las futuras interpretaciones de la obra.

Es por ello que la cronología del arcosolio estuvo durante mucho tiempo ineludiblemente unida a la de la lauda. En 1881, el arqueólogo burgalés Leocadio Cantón Salazar, procediendo a una limpieza del epitafio - ya localizado en su falsa ubicación — recogía el año 1075 (ERA MCXIII) ${ }^{34}$. Esta opinión fue compartida por Rodrigo Amador de los Ríos ${ }^{35} \mathrm{y}$, más tarde, por Ramón Menéndez Pidal en un muy concienzudo trabajo sobre la leyenda de

Romanos y de San Pedro de Arlanza y otros». Ms de la Biblioteca de la Real Academia de la Historia, inscripción n.o 24). Esta obra perdida, y seguramente llevada a cabo con posterioridad a la Crónica de España, en donde repetiría el dato ofrecido por Garibay, fue consultada en 1790 por José Cornide, recogiendo esta interesante noticia. Su transcripción fue la reproducida por: Emil Ernst Hubner, Inscriptiones Hispaniae christianae. Berlin 1871, p. 88 (n. $\left.{ }^{2} 282\right)$.

${ }_{29}$ A ello se añadía una desconcertante inscripción en el frontal de la tapa del sepulcro relativa a Mudarra: «VALIC KEBBIEICE MUDARRA QEL OBIB» (Rafael Monje: «El monasterio de San Pedro de Arlanza» (1847), p. 223). Un año después, en 1849, la casa Gaspar y Roig editaba la Historia de España de Mariana, anotada por el político liberal Eduardo Chao, incluyendo un grabado, copiado directamente del aparecido en el artículo de Monje a juzgar por la reproducción de los mismos errores (Juan de Mariana: Historia General de España. Madrid 1849, tomo I, p. 397). Sobre esta cuestión ver: Isidro Gil: «El monasterio de San Pedro de Arlanza». La Ilustración Española y Americana, 30 de julio de 1887, p. 62; Ríos: Burgos (1888), pp. 898-899; Menéndez Pidal: La leyenda de los infantes de Lara, 1934 (1896), p. 182, n. ${ }^{\circ} 1$ y 2).

${ }^{30}$ Ríos: Burgos (1888), p. 899.

31 García de Quevedo: Excursiones (1899), p. 203.

32 Jose Pérez Carmona: Arquitectura y escultura románicas en la provincia de Burgos. Burgos 1974 (1959), p. 21

${ }_{33}$ Ya Rodrigo Amador de los Ríos señaló: « ¿...esta segunda inferior lauda ha sido sacada de entre los escombros de la iglesia, no sabemos cuando, y colocada en tal paraje antes de 1881 en que el malogrado Sr. Cantón Salazar 'lavó cuidadosamente' la indicada cubierta y descifró los 'confusos caracteres' allí grabados?» (Ríos: Burgos (1888), pp. 899-900).

${ }_{34}$ Fue Isidro Gil quien dio a conocer la nueva lectura del epígrafe que señalaba: «HOC: IN LOCO: REQVIESCIT: GATIA: DEI: GODO: II: NN: FBRI: IN ERAM: C: XIII» (Isidro Gil: «El monasterio de San Pedro de Arlanza» (1887), p. 60, grabado n. ${ }^{9} 5$ y p. 62).

${ }^{35}$ Ríos: Burgos (1888), 895; id, Las ruinas (1886), 17, n. ${ }^{\circ} 1$. 

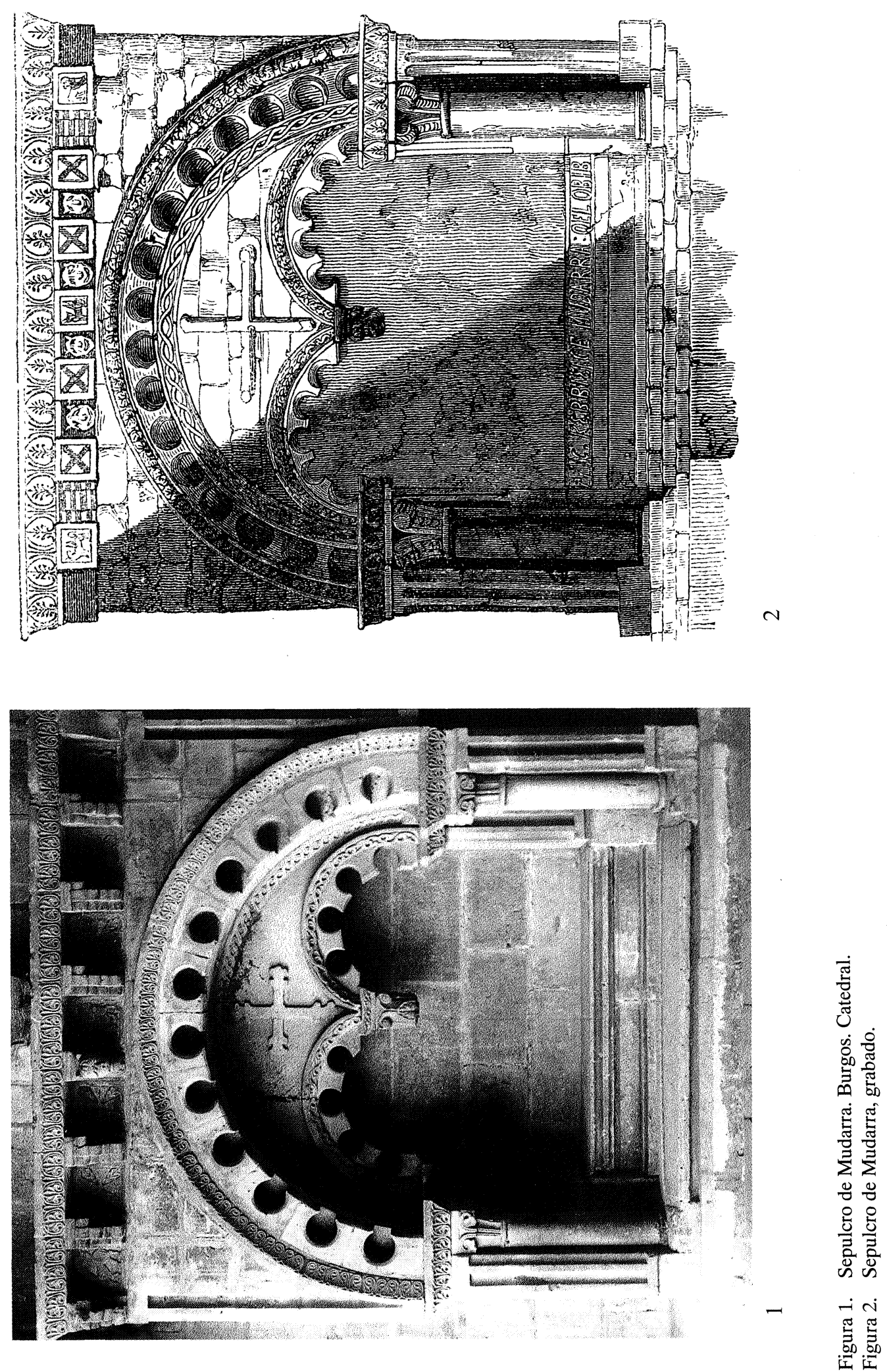
los Infantes ${ }^{36}$. Sólo años después de la traslación del conjunto de la obra -lauda y arcosolio- a su actual emplazamiento en la catedral burgalesa, la crítica histórico-artística, quizá buscando la concordancia cronológica entre el monumento sepulcral y el edificio románico iniciado en 1080 según una lápida hoy perdida y dada a conocer por Rodrigo Amador de los Ríos en $1888^{37}$, reinterpretó una vez más la lectura, considerando los primeros años del siglo XII para su fecha de realización. En 1926 Arthur Kingsley Porter, al tratar sobre la epigrafía del sepulcro románico del hijo de Pedro Ansúrez (c. 1093), había hecho referencia indirecta a la «tomb of Godo» señalando el año $1103^{38}$. Algo más tarde Gómez Moreno propuso el año 1105 (ERA MCXLIII en vez de MCXIII), basándose para ello en un pequeño trazo horizontal en el rasgo superior derecho del numeral «X» ${ }^{39}$. Esta interpretación, avalada por el prestigio del sabio granadino que, aunque con alguna duda, todavía asociaba la lauda con el monumento ${ }^{40}$, fue seguida por Torres Balbás ${ }^{41}$, Gudiol y Gaya ${ }^{42} \mathrm{y}$, en general, por toda la historiografía del arte posterior ${ }^{43}$.

Sin embargo, un análisis objetivo del epígrafe dificulta la lectura propuesta por Gómez Moreno, dando por supuesta la imposibilidad de una adscripción de la lauda al arcosolio en cualquiera de las fechas planteadas. Es notorio lo lejos que se encuentra la escultura de cronologías de románico pleno. Así pues, lo único probadamente cierto es que un 4 de febrero de 1075 (ERA MCXIII), sólo cinco años antes de que la comunidad benedictina de Arlanza procediera a iniciar las obras de la iglesia románica, falleció una mujer a la que se enterró en el monasterio ${ }^{44}$. En el siglo XVI su sepultura se encontraba junto a otra desconocida — la asociada, según Garibay, con el personaje de Mudarra — en uno de los nichos de la sala capitular.

${ }^{36}$ Añadía que el sepulcro era «de igual fecha y estilo que el trozo de pared exterior de la primitiva fábrica de la casa conservado en las edificaciones posteriores» (Menéndez Pidal: La leyenda de los infantes de Lara, 1934 (1896), p. 181). Desde entonces las diversas síntesis divulgativas reprodujeron esta fecha de 1075 para datar el sepulcro (Emile Bertaux: «La sculpture chrétienne en Espagne des origines au XIVe siècle». En: Histoire de l’Art (dir. André Michel). Paris 1938 (1906), vol. II (1), p. 241; «Pedro de Arlanza». En: Enciclopedia Universal llustrada Europeo-Americana, Madrid 1920, t. XLII, pp. 1276-1278).

37 Ríos: Burgos (1888), p. 907; Las ruinas (1896), p. 10.

38 Arthur Kingsley Porter: «Leonesque, Romanesque and Southern France». The Art Bulletin, VIII (1926), p. 243. También en: Spanish Romanesque Sculpture, New York 1969 (1928), I, n.ํ5ㄹ 592, p. 130. En 1941 Walter Muir Whitehill tan sólo citaba la obra (Spanish Romanesque Architecture of the Eleventh Century. Oxford 1941, p. 202, n.․ 4).

39 Manuel Gómez Moreno: El arte románico español. Esquema de un libro. Madrid 1934, p. 96.

40 Su desconfianza hacia una datación tan temprana se concentraba en las columnas «con garras de hoja y capiteles de aspecto gótico», aunque finalmente, y como se ha dicho, apostó por ella (Gómez Moreno: El arte románico (1934), pp. 96-97).

Leopoldo Torres Balbas: «Los modillones de lóbulos. Ensayo de análisis de la evolución de una forma arquitectónica a través de diez y seis siglos». Archivo Español de Arte y Arqueología, 34 (1936), p. 83.

${ }^{42}$ «También escapó de la ruina, y hoy se guarda en el claustro alto de la catedral de Burgos, un sepulcro llamado de Mudarra, pero que correspondería a una dama si suponemos que las palabras «FAMULA DEI GODO IN ERA MCXIIII», insertas en una losa aparte, se refieren al personaje sepultado. La tal fecha de 1105 se aviene como el último momento del arte de Arlanza. Todo se había hecho más suntuoso y lleno de gracia desde 1080». Sin embargo, consideraban que el recurso del arco abarcante de dos geminados con capitel suspendido se asemejaba «a cosas del siglo XII» (José Gudiol Ricart / Juan Antonio Gaya Nuño: Arquitectura y escultura románicas («Ars Hispaniae», V). Madrid 1948, p. 233).

${ }_{43}$ Pérez Carmona: Arquitectura y escultura, 1974 (1959), pp. 46-47; Luis María de Lojendio y Abundio Rodríguez: Castilla/L., Burgos, Logroño, Palencia y Santander. Madrid 1978, p. 356. Consecuentemente, algunas obras de divulgación sobre el románico recogen esta cronología, como es el caso de Fray Valentín de la Cruz: «El período románico». En: Arte burgalés. Quince mil años de expresión artística. Burgos 1976, p. 89.

${ }_{44}$ Isidro Gil señalaba que «no sería aventurado suponer que el abad de aquel monasterio, D. Gotón o Gatón, a quien mencionan Yepes y Flórez» («El monasterio de San Pedro de Arlanza» (1887), p. 62). Por su parte Luciano Huidobro la hacía «madre de Don Gundisalvo Gotiz probablemente» (Huidobro: «El monasterio de S. Pedro de Arlanza» (1924), pp. 204-207) y José Pérez Carmona trataba de identificarla con una hija de 

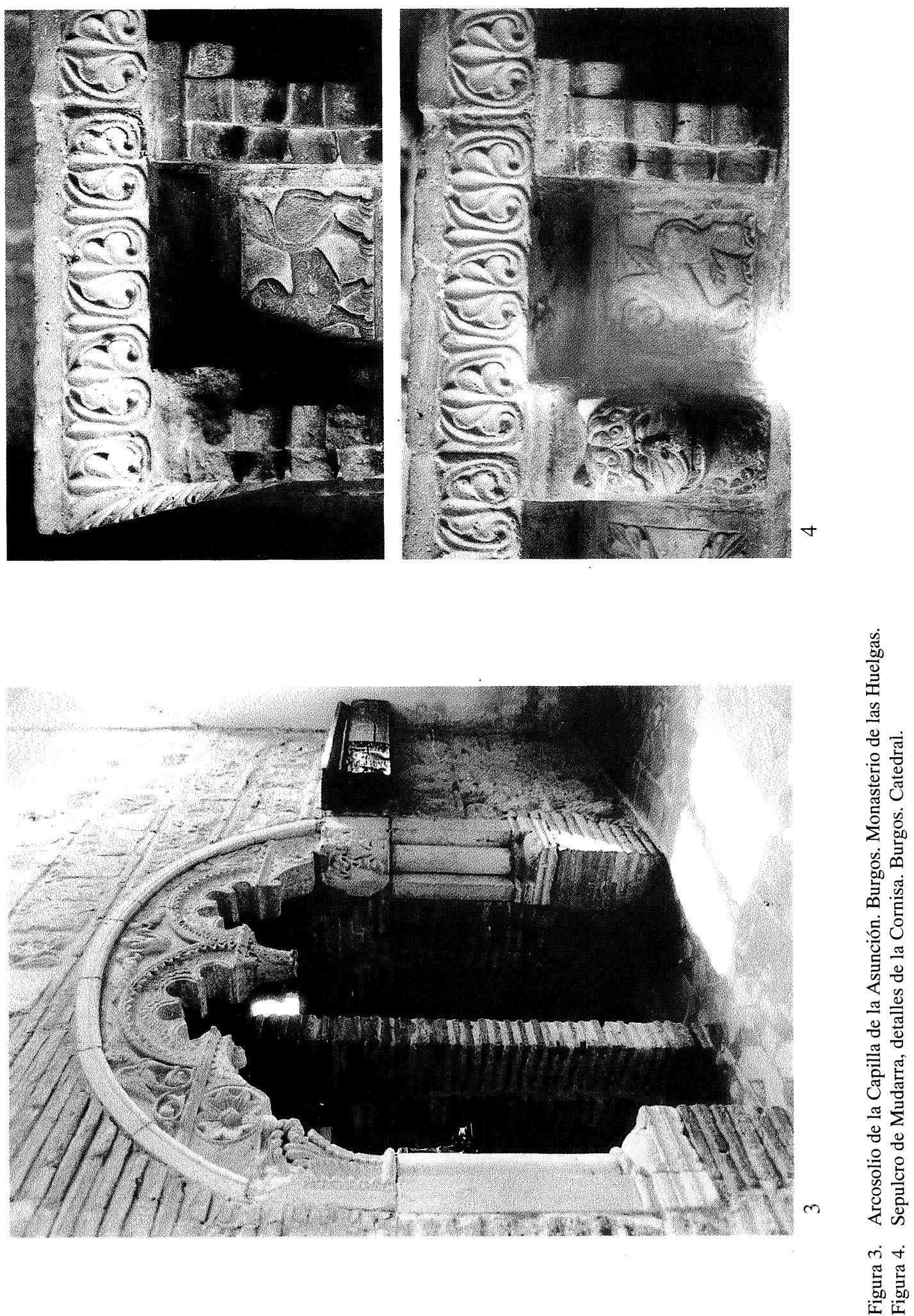
Análisis compositivo y estilístico del arcosolio.

Se trata de un lucillo descontextualizado (altura: 3,34 m; anchura: 3,16 m; profundidad: 0,95 m) de evidentes reminiscencias clásicas, solucionado mediante un gran arco de lóbulos en herradura que cobija otros geminados, también con arquitos ${ }^{45}$. Ambos rematan en un capitel suspendido, labrado por su cara inferior. Dentro de un pretendido arcaísmo se desarrolla un léxico ornamental de gran austeridad, inserto en una original estructura arquitectónica. En lo concerniente al resto de la escultura, su propia desornamentación elude la dirección estética más común del románico tardío, en el cual el horror vacui se alza como uno de sus rasgos definitorios. Es, pues, un ejemplo hasta cierto punto atípico dentro de las realizaciones de este momento. El tímpano se decora únicamente con una cruz trebolada o de San Lázaro, de tipo bastante común — variante de la de Calatrava—, con un pequeño cuadrado en su centro ${ }^{46}$. En el tejaroz se alternan modillones de rollo ${ }^{47}$ con metopas representando cruces griegas, dos leones y un grifo. Este recurso, eminentemente clásico, aparece ya en las primeras manifestaciones plenorrománicas de envergadura como son las cornisas de la catedral de Santiago o las de la catedral de Jaca.

La solución de un arco abarcante y dos más pequeños con lóbulos ultrasemicirculares unidos por un capitel volado, la encontramos en otras obras, como la ventana occidental del pórtico de Rebolledo de la Torre, realizado en 1186 por Juan de Piasca ${ }^{48}$, o, como ya apuntara Pérez Carmona ${ }^{49}$, en el también arcosolio funerario de la capilla de la Asunción en Las Huelgas (fig. 3). Más tardíamente, ya en el siglo XIII, las dos ventanas altas del muro occidental exterior del vecino monasterio de Santo Domingo de Silos se presentan, asimismo, con un pseudomainel rematado en un capitel que también se labra en su parte inferior. $\mathrm{O}$ en un contexto más alejado, la muy restaurada portada meridional de la iglesia de Santiago del Burgo (Zamora).

Gonzalo Salvadores (Pérez Carmona: Arquitectura y escultura románicas, pp. 46-47). Asimismo sabemos que tras la reforma de la iglesia por parte de los Colonia a fines del siglo XV se trasladaron muchas lápidas a otros lugares del monasterio lo que ha hizo pensar a Luciano Huidobro en la posibilidad de que el arcosolio pudiera haberse localizado originalmente en el templo («El Monasterio de S. Pedro de Arlanza» (1924), pp. 204-207).

45 Los arcos polilobulados aparecen adaptados a portadas y marcos más modestos desde mediados de siglo como es el caso del frontal del refectorio de San Salvador de Oña (1141) (José Luis Senra: «La irrupción borgoñona en la escultura castellana de mediados del siglo XII». Anuario del Departamento de Historia y Teoría del Arte (Universidad Autónoma de Madrid), vol. IV (1992), pp. 42-43, fig. 2; «L'influence clunisienne sur la sculpture castillane du milieu du XIIe siècle: San Salvador de Oña et San Pedro de Cardeña». Bulletin Monumental, 153/III (1995), pp. 267-292). Sobre la amplia difusión de este elemento decorativo durante el período románico: Katherine Watson: French Romanesque and Islam. Andalusiam elements in French Architectural Decoration c. 1030-1180. Oxford 1989.

46 Cruces semejantes presentaban al menos dos de los sepulcros desaparecidos conservados en la iglesia (Luciano Huidobro: «El monasterio de S. Pedro de Arlanza» (1924), pp. 204-205) así como en otras del pórtico de la iglesia del monasterio de Las Huelgas, fechado a comienzos del siglo XIII. Concretamente aparecen como único motivo decorativo en el frontal de la caja, en sus lados menores y en la tapa, inscritas en marcos cuatrilobulados (M.․․ Jesús Gómez Barcena: Escultura gótica funeraria en Burgos. Madrid 1988, pp. 193-194, fig. 145). Sobre este sepulcro también: Manuel Gómez Moreno: El Panteón Real de Las Huelgas de Burgos. Madrid 1946, p. 13. Ya hemos señalado cómo una silueta similar a la del frontispicio presentaba la cruz que, según Sandoval, utilizó el conde Fernán González como enseña heráldica y que formó parte del escudo de Arlanza junto al castillo y las llaves de San Pedro (v.n.8).

${ }_{47}$ Sobre el amplio marco cronológico de la utilización de estos motivos que ejemplifican un auténtico casticismo ornamental de la arquitectura castellano-leonesa, es ya clásico el aludido trabajo de Lepoldo Torres Balbás (v.n.42).

${ }_{48}$ Leopoldo Torres Balbas: «Un maestro inédito del siglo XII». Archivo Español de Arte y Arqueología, I (1925), pp. 321-322; Pérez Carmona: Arquitectura y escultura románicas en la provincia de Burgos, 1974 (1959), pp. 43-44, 93 y 175. Ver: Marcel Durliat: El arte románico en España. Barcelona 1972 (1962), ill. 154. Otra iglesia que introduce el parteluz suspendido es la de San Lorenzo de Vallejo (Ver: Lojendio / Rodríguez: Castilla/L. 1978 (1966), ill. 69).

49 Pérez Carmona: Arquitectura y escultura románicas, 1974 (1959), p. 122. 
Por lo que respecta al arcosolio de la Asunción de las Huelgas —en el ángulo SE de las Claustrillas-, Manuel Gómez Moreno lo identificó con el enterramiento del infante Fernando, primogénito de Alfonso VIII, fallecido en octubre de 1211 con sólo veintidós años «preso de la fiebre» ${ }^{50}$. La coincidencia en la longitud del sepulcro respecto al hueco del arcosolio $-1,90 \mathrm{~m}-$ fue el argumento utilizado para fecharlo ${ }^{51}$. Y, como ya apuntó el propio maestro granadino ${ }^{52}$, existe una indudable semejanza entre sus capiteles y los de los machones del ángulo SE de la panda septentrional de las Claustrillas. Así, una neta identidad de características plásticas convierte al arcosolio y a la galería más próxima en coetáneas ${ }^{53}$. Sin embargo, a partir de análisis estilísticos más recientes, avalados al menos de forma parcial por la documentación, este pequeño claustro ha sido considerado — también por Gómez Moreno ${ }^{54}$ — como la construcción más temprana del conjunto burgalés, por lo que habría sido llevada a cabo a partir de 1180, dando como válidas las fechas más precoces. Conjugando estos criterios y aplicando consecuentemente una lógica estrictamente crono-estilística se podría considerar que el arcosolio pudiera pertenecer al infante Sancho, primer heredero del trono, nacido en 1180 y fallecido prematuramente poco más de un año después, coincidiendo con la propia fundación de las Huelgas ${ }^{55}$. Pero más allá de la inevitable certeza de que su sepulcro tan sólo mide $0,88 \mathrm{~m}$., esta línea de interpretación se desmorona al comprobar que el arcosolio parece haber sido trasladado de su ubicación original, convirviéndolo en puerta de acceso a una pieza anexa a la capilla de la Asunción. Es evidente que su nuevo montaje eliminó la parte inferior del tímpano estrechando, por consiguiente, el hueco destinado al sepulcro. Es decir, no se respetaron las medidas primigenias, lo que invalida la propuesta de Gómez Moreno. Ultimamente José Luis Hernando, centrándose en criterios de estilo, se muestra partidario de conceder tanto al sepulcro de Las Huelgas como al de Arlanza una datación «ostensiblemente anterior a 1211» ${ }^{56}$.

En resumen, podemos afirmar que se trata de una solución arquitectónica de carácter funerario que aparece en un amplio espectro cronológico. Así, arrancando de finales del siglo XII se desarrolla hasta entrado el XIII, resultando difícil acotar una datación específica dada la

50 Rodrigo Jiménez de Rada, que fue testigo directo del acontecimiento, señala: «Y así falleció en la fortaleza de Madrid, en la diócesis de Toledo, en el mes de octubre de la era 1249, con breve vida y amplia gracia y virtud. Fue enterrado en el monasterio de Santa María la Real, cerca de Burgos, por Rodrigo, arzobispo de Toledo, y muchos sufragáneos y destacados seglares y religiosos» (Rodrigo Jiménez de Rada: Historia de los hechos de España (Juan Fernández Valverde, ed.). Madrid 1989, VII, xxxvi, 306). Los Anales Toledanos confirman la noticia: «Murió el Infant D. Fernando dia Viernes en la noche en XIV dias doctober, Era MCCIL» (Enrique Flórez: España Sagrada. Madrid 1767. tomo XXIII, p. 395).

${ }_{51}$ «Sin duda se hizo para guardar el cuerpo de Fernando, el hijo de Alfonso VIII fallecido en 1211 y primer adulto sepultado aquí, según ya sabemos; el hueco del lucillo, que mide 1,90 m., coincide en longitud exactamente con el ataud del infante, y ello basta para identificarlo» (Gómez Moreno: El Panteón Real de Las Huelgas, pp. 13-14, lám. XIV; «Historia y arte en el Panteón de las Huelgas de Burgos». Arbor, V-VI (1947), p. 403). Sobre este sepulcro ver también: Ricardo del Arco: Sepulcros de la Casa Real de Castilla. Madrid 1954, pp. 243-244; Pérez Carmona: Arquitectura y escultura, p. 122; Gómez Barcena: Escultura gótica funeraria en Burgos, (1988), pp. 193-194. fig. 146; José Luis Hernando Garrido: «Las Claustrillas de Las Huelgas, San Andrés de Arroyo y Aguilar de Campoo: los repertorios ornamentales y su eclecticismo en la escultura del tardorrománico castellano». Anuario del Departamento de Historia y Teoría del Arte (Universidad Autónoma de Madrid), IV (1992), pp. 59-60; Id, Escultura tardorrománica en el monasterio de Santa María la Real en Aguilar de Campoo (Palencia). Aguilar de Campoo 1995, pp. 130-131.

52 Gómez Moreno: El panteón real de Las Huelgas (1946), p. 14.

53 Sobre estos paralelismos ver: José Luis Hernando Garrido: «Las Claustrillas de Las Huelgas...» (1992), pp. 53 y ss.; Escultura tardorrománica en el monasterio de Santa María la Real en Aguilar de Campoo, pp. 130-131.

${ }_{54}$ Para Gómez Moreno «lo primitivo son las Claustrillas, con su capilla aneja, y otras dos de carácter mudéjar también. Allí hubieron de ser depositados todos los susodichos difuntos, no en suelo consagrado, pues esto iba contra la iglesia cisterciense, sino quedando sus ataúdes insepultos, sobre soportes de piedra, tallados como delanteras de león generalmente» (Gómez Moreno: El panteón (1946), p. 8).

55 Arco: Sepulcros (1954), p. 242.

56 Hernando Garrido: «Las Claustrillas de Las Huelgas...» (1992), pp. 59-60. 

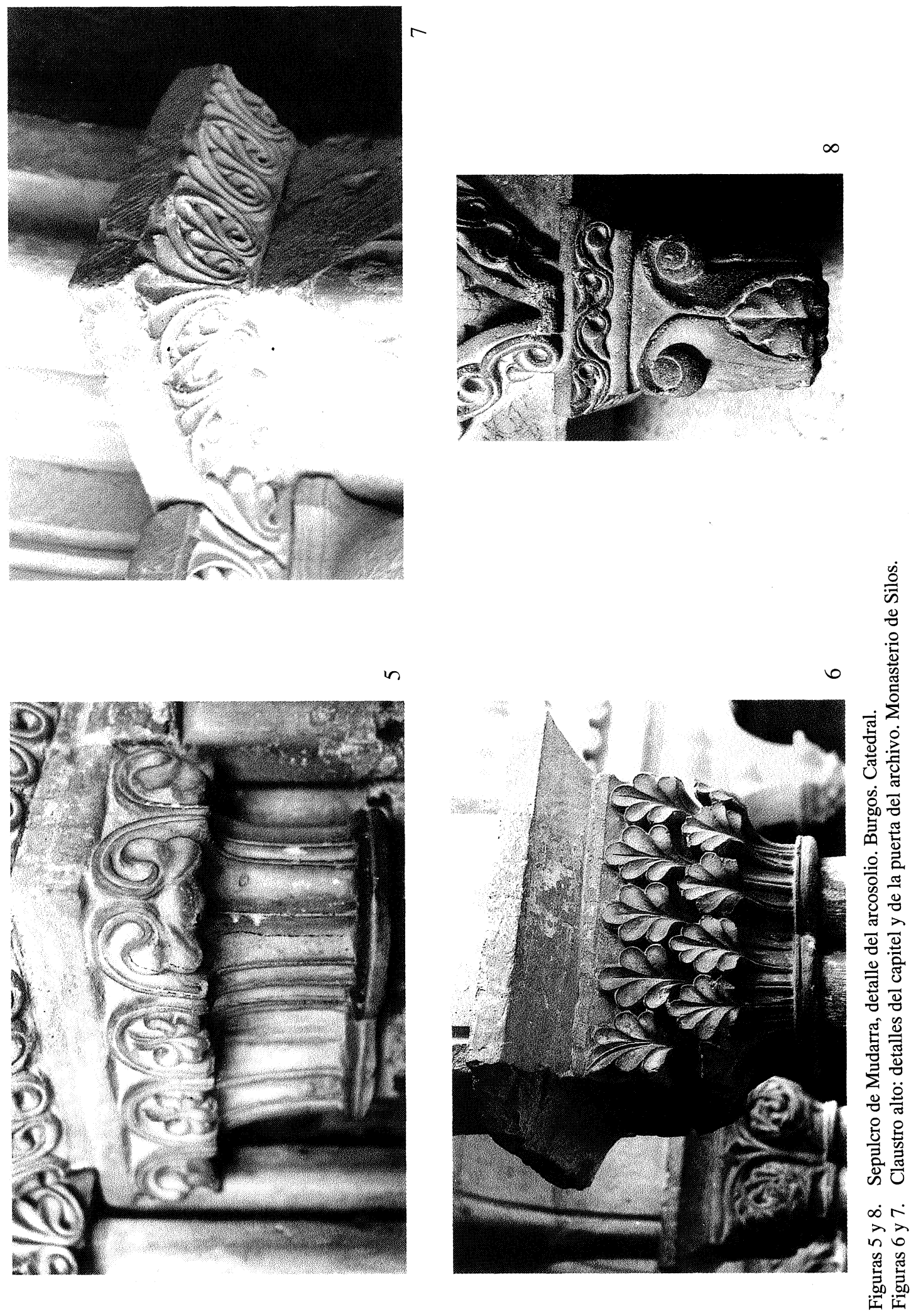
gran inercia escultórica de este momento, aunque bien podría situarse en las inmediaciones del cambio de siglo. Muy posiblemente nos encontremos ante un representativo ejemplo de una tipología que consistiría en monumentalizar las sepulturas, hasta entonces escasamente significadas, mediante un marco arquitectónico. Por otro lado, hay que señalar que las líneas estilísticas de buena parte de los escasos restos del pequeño claustro tardorrománico arlantino que se conservan, invitan a pensar en cronologías en torno a ambos márgenes de 1200.

Respecto a la estilística escultórica, ninguno de los variados fragmentos de la colección lapidaria de Arlanza conservados en la sacristía se asemejan a la escultura del arcosolio. Tampoco se observa similitud respecto a los escasos restos que se mantienen «in situ» en la panda oriental del claustro. Es en el vecino monasterio de Silos en donde a las concomitancias referidas hay que añadir algunas otras de orden estrictamente estilístico. Los capiteles (morfología de la cesta, solución de tallos ${ }^{57}$, collarinos) (fig. 5) y gran parte del aparato ornamental (figs. 4 y 8) encuentran una considerable conexión con algunas de las realizaciones, también de la panda occidental del claustro alto del monasterio (figs. 6 y 7) ${ }^{58}$. A ello hay que sumar que los capiteles del sepulcro arlantino y los de esa parte del claustro silense encuentran una común identidad modular ${ }^{59}$. Carecemos de estudios sistemáticos de este último a pesar de haber sido tratado desde antiguo ${ }^{60}$. A mi modo de ver, la opinión más ponderada — viable, al menos respecto a sus inicios- sigue siendo la propuesta por Pérez de Urbel, para quien sería llevado a cabo entre 1180 y 1200, lo que concuerda con las líneas plásticas del arcosolio ${ }^{61}$.

¿A quién pertenecería esta suntuosa sepultura? Los datos de los siglos XVI-XVII sobre los sepulcros del claustro son demasiado inconcretos para posibilitarnos plantear una hipótesis con un mínimo respaldo argumental. Una de las pocas sepulturas que permiten una localización, y que por la cronología del difunto resultaría de interés, señala que el obispo de Burgos Marino Maté (1181-1200), antiguo monje de Arlanza, fue enterrado en el monasterio, concretamente «en la Puerta, que de el Claustro se entra en la Iglesia, a la parte de mano derecha» ${ }^{62}$. Siendo así, y teniendo en cuenta los dos accesos del claustro al templo —oriental y occidental—, parece que se estaría refiriendo a aquél de traza renacentista dispuesto junto a la sala capitular - como además concluye su inscripción («Hic iacet Martinus bugensis episcopus») — y no al llamado sepulcro «de Mudarra», que ya entonces se localizaría junto a la puerta oeste del claustro ${ }^{63}$.

57 La forma bífida de los tallos ascendentes aparece en otras obras de la segunda mitad del siglo XII, como el claustro de la colegiata de Santillana del Mar (Cantabria) (ver: Miguel Angel García Guinea: El románico en Santander. Bilbao 1979, tomo II, p. 233, fig. 337, capitel 22).

58 La actual puerta del archivo presenta cimacios de una acusada proximidad a los del arcosolio arlantino, al igual que ciertos fragmentos conservados en el monasterio.

59 0,45 m de longitud en la parte superior de la cesta y $0,30 \mathrm{~m}$ de altura, por señalar las medidas más representativas. En este sentido, además de las diferenciaciones escultóricas conviene subrayar las divergencias modulares que presenta el propio sobreclaustro silense.

Dom Eugène Roulin: «Les cloîtres de l'abbaye de Silos». Revue de l'art Chrétien, IX (1910), pp. 11-12, Ramiro de Pinedo: «El claustro de Silos y sus inscripciones». Boletín de Santo Domingo de Silos, 21 (1918-1919), pp. 269; Pérez Carmona: Arquitectura y escultura románicas (1959), pp. 215-217.

${ }^{61}$ Fray Justo Pérez de Urbel: El claustro de Silos. Burgos 1975, p. 217, cronología ya avanzada en la primera edición de esta obra (1930). Un más reciente trabajo de Félix Palomero Aragón («Los maestros del claustro alto de Silos». En: El románico en Silos. IX Centenario de la consagración de la iglesia y claustro. Burgos 1989, pp. 225-267) propone como excesivo terminus post quem la referencia documental sobre las obras en el claustro en 1158 («opera claustri») extendiéndolas hasta comienzos del XIII (pp. 246-247).

62 Alonso Núñez de Castro: Coronica de los señores reyes de Castilla Don Sancho el Deseado. Don Alonso el Octauo. y Don Enrique el Primero. Madrid 1665, p. 184.

63 Tampoco existe unanimidad en la historiografía moderna sobre la sepultura del obispo burgalés (Ríos: Burgos (1888), pp. 902-903, n. 1). 